\title{
Thou shalt not get fat: Medical representations and self-images of obesity in a Mediterranean society
}

\author{
Mabel Gracia-Arnaiz \\ Department of Anthropology, Philosophy and Social Work, University Rovira i Virgili, Tarragone, Spain; mabel.gracia@urv.cat \\ Received 8 February 2013; revised 9 April 2013; accepted 15 May 2013 \\ Copyright (c) 2013 Mabel Gracia-Arnaiz. This is an open access article distributed under the Creative Commons Attribution License, \\ which permits unrestricted use, distribution, and reproduction in any medium, provided the original work is properly cited.
}

\section{ABSTRACT}

This paper examines the link between lipophobia and representations and experiences of obesity in Catalonia (Spain) from two points of view: that of the physicians and other health professionals who diagnose and treat obesity as an illness, and that of their patients, especially those between adolescence and early adulthood. The qualitative data demonstrate that the increasing social rejection of fat people can be traced not only to moralizing discourses on "excessive" food consumption or the commodification of slenderness and health, but also to the recent definition of obesity as a disease. The medicalization of fatness, far from helping to destigmatize obesity, is becoming a way of re-signifying it in moral terms. While doctors' and patients' perspectives diverge in some ways, they converge in others. In this text, I focus on the points of convergence arguing that biomedical understandings of obesity and overweight are characterized by a profound ambivalence. Young patients are regarded both as innocent victims of a permissive consumer society, and guilty of not following doctors' orders. Although the family is held accountable for overweight or obesity in children, as young people become more independent, guilt is individualized and environmental causes are limited to inappropriate diet and insufficient exercise. Most narratives of young people with weight problems reflect similar ideas about the causes and the responsibility for obesity. Their acceptance of the basic premise that deviating from weight standards and rules for healthy eating are voluntary actions leads them to lose faith in themselves. The stigmatization of obesity thus becomes a vicious circle: the obese acceptance-even consider normalthe incriminations leveled at them, and blame themselves for their situation and their inability to prevent it.

Keywords: Obesity; Medicalization; Lipophobia; Stigmatization; Young People

\section{INTRODUCTION}

For several years, I have been attempting to understand how and why specific eating behaviors have become health problems and how dietary recommendations for the maintenance of normative body weight are constructed in modern complex societies. The present etnographic study ${ }^{1}$ examines the rise of lipophobia as a consequence of the medicalization of fatness and the emergence of an eleventh commandment: thou shalt not get fat. Whereas my prior research has focused on the sociocultural context of being thin in Spain [1,2], this article moves to the other end of the continuum, analyzing the link between lipophobia and representations and experiences of obesity in Catalonia from two points of

\footnotetext{
${ }^{1}$ In 2008, with the support of the MEC [Ministry of Education and Science] and the Generalitat of Catalunya, I began an ethnographic study in Catalonia (Spain) about the social dimensions of obesity which was part of a broader state-wide program of research focalized in two specific projects The emergence of obesogenic societies or obesity as a social problem (2009-07683) and The Images and experiences of obesity in young people (2008-00017). Work is being carried out on three main levels: a) a bibliographical review that focuses on socio-anthropological and Spanish epidemiological literature of obesity; b) the study of Spanish nutritional recommendations and health strategies; and c) a medical ethnography carried out on representations and practices in obesity in the Catalan health care system. I have worked in two public hospitals and two primary care centres. In order to be able to apply techniques of qualitative analysis (direct observation, in-depth interviews and focal groups), I have selected quite a low number of informants. On the one hand, I interviewed 20 young people diagnosed with obesity between 15 and 29 years old, and 5 adults between 30 and 35 years old that they had been obese during their youth. Of these $56 \%$ were women and $44 \%$ men. A total of $50 \%$ were from the low to lower-middle classes, $38 \%$ from the middle-middle class, and $12 \%$ from the upper-middle class. On the other hand I also included in the study 10 health professionals (endocrinologists, dieticians, hospitals, family doctors).
} 
view: that of the physicians and other health professionals who diagnose and treat obesity as an illness, and that of their patients, especially those between adolescence and early adulthood. I focus on young people because their behavior is often associated with the irrationality and irresponsibility characteristic of the "process of maturation”, a biological metaphor for their resistance to authority - in this case, to medical recommendations concerning diet and exercise.

While doctors' and patients' perspectives diverge in some ways, they converge in others, and in this article I wish to focus on the points of convergence. I argue that biomedical understandings of obesity and overweight are characterized by a profound ambivalence. Patients are regarded both as innocent victims of a permissive consumer society, and guilty of not following doctors' orders. In Spain, unlike other countries [3], the terms of public debate about obesity are not polarized in terms of "individualizing" or "systemic" frames. Instead, while experts point to all sorts of possible social causes (chief among them fast food and passive forms of leisure), interventions focus, paradoxically, on individual behaviors. The paradox is especially evident in the case of overweight young people. Although the family is held accountable for overweight or obesity in children, as young people become more independent, guilt is individualized and environmental causes are limited to inappropriate diet and insufficient exercise. Surprisingly, even when they recognize the multifactorial character of obesity, health professionals stress individual eating habits and body behaviors, paying little attention to their structural causes. Most narratives of young people with weight problems reflect similar ideas about the causes and the responsibility for obesity. Their acceptance of the basic premise that deviating from weight standards and rules for healthy eating are voluntary actions leads them to lose faith in themselves. The stigmatization of obesity thus becomes a vicious circle: the obese acceptanceeven consider normal-the incriminations leveled at them, and blame themselves for their situation and their inability to prevent it [4]. The recognition of any problem as a disease would normally exempt the sufferer from blame, but the medicalization of obesity has not served to limit the stigmatization and discriminatory treatment to which obese persons are subject because of their body size. Instead, by making obese persons individually responsible for their fatness, biomedical discourse fuels and even legitimizes lipophobia [5].

\section{LIPOPHOBIA AND THE MEDICALIZATION OF FATNESS}

The negative attributes currently associated with obesity cannot easily be understood without attention to the historical forces that have contributed to their develop- ment in Western societies. Lipophobia [6] or fatphobia [5], understood as the systematic rejection of fatness and the fear of getting fat, is a relatively recent phenomenon in Western countries. Although concern about weight and body shape increased over the course of the 20th century, the problematization of excess weight is by no means exclusive to the present $[7,8]$. In classical antiquity and the Judaeo-Christian tradition, cultural attitudes toward fatness were ambivalent, fluctuating between mockery and respect, disdain and approval. Fatness was connected not only with health, both good and bad, but also with sensuality.

Although biomedicine has tended to neglect the role of cultural images and practices, biomedical perceptions of fatness are influenced by them. Medical knowledge shapes social practices [9] but, like other forms of knowledge, it is also subject to them. This reciprocal relationship gives rise to historically specific perceptions of the body, food and illness. Over the course of the 20th century, the phenomenon of lipophobia became increasingly entrenched [10] as a result of the changing epistemological status of fatness in medicine, and shifts in its social meaning. The present negative view of fatness, then, has been constructed over time and influenced by a variety of forces: the morality of the Christian West, which calls for moderation and restraint and scorns gluttony; the evolution of scientific knowledge, which has demonstrated a close connection between diet, illness and health; and the changes that have taken place in cultural representations of the ideal body and in bodily practices.

The culturally and historically specific “desirable body” not only mirrors social context, but also conceals power relations [11]. As diet and body have undergone a process of medical normativization [12], fat people have been increasingly stigmatized as nutritional delinquents [13]. Although medicine has identified numerous functional causes of the excessive accumulation of fat (metabolic, genetic, medicinal, hormonal), fat people are regarded as big eaters, people who eat too much. This perception is partly linked to the moralistic interpretation that science has made of the so-called societies of abundance. The current definition of obesity as a pathology caused by the excessive accumulation of fat coincides, curiously enough, with the only period in the history of humanity in which, in the developed societies, food is available in abundance as a result of the changes in food production and distribution that took place during the second half of the 20th century. Neocapitalism has made easily available an unprecedented variety of foods in quantities that permit and even invite unlimited consumption, while at the same time putting in place rigid nutritional standards of an almost puritanical character [14]. In industrialized societies, fatness is a sort of "defect” in the process of civilization [15]. The pathological 
images surrounding obesity express a preoccupation with social order and have acquired a punitive significance in a way that parallels another highly culturally elaborated disease: cancer $[16,17]$. Excess weight as the consequence of overeating and laziness threatens the social order, and the transgressors must be brought back into line.

While many forms of embodied difference-racial, ethnic, gender-are characterized positively as "human diversity", obesity is an exception to this rule. While slender bodies are defined as morally, medically, aesthetically and sexually desirable, fatness signifies laziness, ill health and ugliness. Thinness has been progressively disassociated from poverty and illness, and reinterpreted as a sign of self-discipline, health and beauty $[18,19]$. Of the two Western stereotypes about fatness [6] - the jolly, sweet-toothed fat people whose good humor makes them socially accepted, and the gluttonous fat people whose self-centeredness and laziness lead to social rejection-the latter has finally triumphed: fat people are thought to have insatiable appetites and no self-discipline. Slimness is portrayed not only as attractive but also as a sign of moderation, self-control and effort. Fatness, on the other hand, is equated with self-indulgence and regarded as not only physically unhealthy but also behaviorally obscene. The resulting stigmatization of fat persons has a considerable impact on their personal relations and daily life.

If lipophobia is the systematic fear or rejection of fat and fatness, lipophobism [20], a process that emerges from and is shaped by the structures of obesogenic societies, is the discriminatory treatment of fat people. By incorporating many of the value judgments entailed in lipophobism, the medicalization of fatness has contributed significantly to stigmatizing overweight persons. This confluence of ideology and social practice is reflected in the conceptualization of obesity as an "avoidable" disease.

In the course of two decades, medicine has changed the epistemic status of obesity [4]. It is no longer regarded as a risk factor for other diseases; it is now itself understood as a chronic disease defined by the excessive or abnormal accumulation of fat produced by a positive energy balance between calories ingested and calories burned. Year after year obesity becomes increasingly prevalent, and mechanisms have been devised to measure and control it. The creation of body weight as a measurement category gave rise to the categories of underweight and overweight as deviations from normal weight [21]. The Quetelet Index or BMI (Body Mass Index) is now the most commonly used indicator to determine healthy weight as a function of a person's height. The optimal BMI is set between 18.5 and $25 \mathrm{~kg} / \mathrm{m}^{2}$. Beneath the lower limit there is a higher mortality/morbidity rate for malnutrition- and cancer-related diseases, and above it, for diabetes, hypertension and cardiovascular problems. Obesity is blamed for the increase in premature deaths and lost years of healthy life, and for rising health care costs [22].

The reconceptualization of obesity as a disease can be traced to the 1985 Consensus Development Conference on the Health Implications of Obesity, when the National Institutes of Health agreed to refer to obesity as a disease. The International Statistical Classification of Diseases and Related Health Problems [23] has two entries for obesity (278.00, 278.01), and the World Health Organization declares it the foremost non-communicable epidemic disease of the 21st century [24]. Some scholars, however, believe that these classifications need further debate. Heshka and Allison [25] question the recognition of obesity as a public health problem because, in their opinion, obesity does not fulfill the criteria conventionally used to determine what is, or is not, a disease. Although it is certainly true that obesity can considerably disturb or impede physical functions, it does not always do so. These difficulties are more common in cases of extreme fatness. The extent of physical deterioration increases with body volume, but this deterioration is by no means inevitable or even common in people with a BMI equal to or above $30 \mathrm{~kg} / \mathrm{m}^{2}$. Unlike morbid obesity, mild or moderate obesity is simply a warning sign, a risk factor for possible future deterioration. The association with any possible harm, though, is only probabilistic. No one can predict with any certainty in which cases obesity will become harmful to health. Since some people who fulfill the criteria for obesity live long lives free of the morbidity statistically associated with overweight, it is problematic to regard obesity as a disease when for many people it involves no illness of any sort. A great many obese people are productive members of society and do not necessarily consider themselves disabled, although they may feel that they are victims of social discrimination.

In the Spanish medical literature, by contrast, there is no debate about whether it is necessary or appropriate to label obesity as a disease in order to take it seriously as a potential threat to health. Obesity is unanimously claimed to be one of the most serious public health problems in the country, and if the increase in clinical and epidemiological research and the proliferation of specialized treatment and prevention programs is anything to go by, it is rapidly being medicalized. This is reflected in increasing demand by physicians for more public investment in prevention and health education.

Like other Western countries, Spain has produced numerous epidemiological studies of obesity [26]. These studies, however, are methodologically highly diverse and therefore their results cannot reliably be compared or 
the evolution of prevalence reliably assessed [27]. For example, because different cutoff points (national or international) have been used, the prevalence of obesity in the population between the ages of 10 and 17 years in 1992 varies from $1.9 \%$ to $10.3 \%$ [28]: a difference of 8 percentage points. Despite divergent findings, however, all the major studies converge on a significant point: in both adults and children, the prevalence of overweight and obesity is significantly higher among those with lower incomes and a lower level of education, particularly among women.

According to the National Health Survey [29], in Catalonia, the percentage of the adult population identified as overweight is one of the lowest in Spain at 35.2\%, while the prevalence of obesity occupies an intermediate position (15.1\%). The prevalence of overweight (16\%) and obesity (7.2\%) among children and pre-adolescents is below the average for Spain as a whole [30]. Despite these relatively favorable numbers, Catalonia is the first autonomous community to have created its own weight control strategy in accordance with the guidelines established by the World Health Organization [31] and the Spanish NAOS Strategy [32]. Called the Plan for Physical Activity Promotion and Healthy Food-PAAS [33], it targets mainly school-age children and adolescents.

In the absence of a serious public health problem, the deployment of this program in Catalonia has been justified by reference to the steadily increasing prevalence of overweight noted in some epidemiological studies [34, 35]. It has become commonplace to speak of the "Mediterranean paradox", a reference to the contradictory nature of this trend in a society whose national cuisine, like that of other Mediterranean countries, is widely regarded as especially healthy. As the rising prevalence of overweight achieves greater acceptance as scientific fact, greater explanatory power is ascribed to cultural factors. PAAS attributes the increase in obesity largely to a decline in healthy eating habits and an increase in sedentary lifestyles: simply put, people eat too much food of dubious nutritional value, and exercise too little. There is no comparative analysis of socio-cultural differences between Catalonia and other countries or other regions of Spain. Epidemiologists define the causal agents as the factors that, taken together, constitute the "obesogenic environment" [36]: from fast food to passive leisure, from family breakdown to the accelerated pace of life, from the general use of heating and mechanized transport to the lack of sports facilities, from food advertising to the lack of nutritional education, among others. These same causes are identified by Le Guen [22] for France, and by Lang and Rayner [37] for the United Kingdom, and they are also adduced by health specialists who emphasize the importance of ecological approaches in identifying the importance of environment in shaping dietary behaviours [38]. Despite this emphasis on environmental factors, however, since overweight is perceived above all else as a problem of "bad" diet and "lack" of exercise, intervention and prevention focus on correcting these trends by encouraging individuals to eat a balanced diet and maintain a program of regular exercise [39].

This focus on the individual pervades the Catalan strategy at all levels. Although PAAS refers to structural social and economic factors, it emphasizes behavioral change and individual responsibility. The solution to the problem is to develop and maintain a healthy lifestyle, which involves - among other things - achieving an energy balance and normal weight by limiting the intake of calories from fats and sugars, eating five portions of fruit/vegetables every day, and exercising daily for at least 30 minutes. These recommendations, however, do not take into account the influence of context on health. The close connection between individual agency and social structure $[40,41]$ has implications for access to health resources and acceptance of dietary and weight guidelines [42], and helps to explain the unequal distribution of fat according to social class and gender in modern societies. As various scholars have pointed out, for example, the increasing feminization of fat [11] is closely related to low income levels [4].

The classification of obesity as an epidemic disease of global proportions neither increases our understanding of its complex etiology nor determines an appropriate response. What it has achieved, however, is the legitimation of dieting as a way of life, largely as a result of what Hacking [21] defines as the "epidemic" of obesity discourses. Clinical interventions, as we shall see below, are full of assumptions about bad habits and individual responsibility, and invariably involve putting patients on a diet even though the success rate is very low. Dietary prohibitions encode anti-fat messages — which the market has successfully exploited-that have also served to increase the stigmatization, suffering and guilt fat people experience.

\section{MEDICAL REPRESENTATIONS AND PRACTICES IN RELATION TO OBESITY}

In Western societies the widely accepted understanding of obesity as a moral failure has helped to shape biomedical conceptions and practices [14], and biomedicine, in turn, has legitimated this view. Catalonia is no exception. Being fat is thought to indicate not only a lack of self-control but also irresponsibility, both for one's own health and to society. These moral judgments circulate freely among clinicians, and are applied with particular harshness to young patients, although not without a degree of ambivalence. Biomedicine simultaneously constructs young fat people both as sick persons who are 
the victims of a permissive consumer society, and also as guilty persons who willfully transgress the normative patterns designed to avoid obesity: a balanced diet and "normal", healthy body weight. The concept of disease normally relieves patients of responsibility for their condition, but in the case of obesity this is not necessarily so. Most of the health professionals interviewed for this study maintain that it is at least in part a self-inflicted condition, the result of a behavioral choice.

Most of the physicians I interviewed agree that obesity arises out of a combination of endogenous factors: genetic, hormonal and metabolic. As one endocrinologist put it, "Some people get fatter than others even though they eat the same... There's probably a genetic component but we don't know how to measure it." Some, like this pediatrician, suggest that energy imbalance is caused by functional issues: "The causes of obesity are multifactorial. Not only do people have to eat a lot and not burn it off; they have to eat a lot, not burn it off and have a metabolism that predisposes them to the condition.” The comment of a family doctor who was willing to accept that obesity is not necessarily a disease also shows that even if it were, this would not exempt the patient from blame: "Some things have been assumed to be true, but they haven't been proved. Not everybody who is overweight is ill. I don't know whether these people should be demonized and told that they are suffering from a disease."

Nevertheless, it is uncommon for health professionals to adopt a relativistic approach. The etiology of obesity is generally located in exogenous factors, particularly in the excessive quantities of unhealthy food consumed. While the physically undemanding nature of modern life is occasionally offered as an explanation (as one physician said, "We have transportation, computers... people don't walk anywhere anymore"), it is more usual for health professionals to blame obesity on individual behavior conceptualized as an unhealthy lifestyle. As an endocrinologist observed, "The obese are people who consume the maximum and expend the minimum.” According to many health professionals, young people are ignorant, perhaps willfully so, about what constitutes a healthy diet, often because their parents are too permissive. Another endocrinologist reasoned that "eating habits acquired at home are very important. If they are not educated from an early age and they are given whatever they like, they will take the easy way out and eat whatever tastes good to them. If the family doesn't lay down the law, they will eat what they like." Physicians see obese children and young people as the product of a society of abundance and fast food, one that sets no limits and encourages parental indulgence. A family physician complained, "Many parents come here with excuses. They say they have tried everything and there is no way they can get their children to eat vegetables or fish. Well, if the parents can't assert themselves, what chance have we got?" This emphasis on the individual makes it easier to blame parents and children for their inability to act rationally and, therefore, legitimates health intervention. As a dietician put it, "If they don't know how to eat properly, they must be taught.”

Accepting that obesity is a disease obliges doctors to intervene and patients to follow a course of treatment. Although medical intervention can involve drugs and surgery, the most common treatment is nutritional rehabilitation: dieting under medical supervision in order to bring calories consumed and calories expended into proper balance. Its aim is to get patients to achieve a normal body weight and maintain it by adopting healthy eating habits [2]. In a twofold process of medicalization and moralization, young people must abandon their "bad" eating habits and acquire a new set of habits that conform to scientific nutritional guidelines. As a dietitian argued, "Your health is not the only reason for eating better. You feel better and fitter if you eat properly." Overweight is regarded as the prelude to obesity, and those who are one or two kilos over their ideal weight are people who are about to fall ill. As a nutritionist expressed it, "Excess fat that is not directly responsible for a physical problem is probably a pre-pathological condition.” A pediatrician articulated the belief, common among physicians, that people gain weight continually throughout the life cycle and that overweight therefore leads inevitably to obesity: "It's absolutely clear that overweight, if you aren't careful, is a slippery slope. Overweight at age 20 will probably be class 1 obesity in adult life.”

Nutritional rehabilitation is intended to ensure that patients recover from the illness not only physically and psychologically, but socially as well, learning "normal" eating habits. Health professionals believe that patients must follow their diet to the letter over months or even years if necessary because it makes them feel secure, provides order in their lives and-paradoxically—helps them to combat their obsession with weight by obsessively controlling what they eat. An endocrinologist explained the medical preference for treatment through lifestyle change: "What we do is education, diet, exercise, etc. If necessary, we use drugs or assess the possibility of bariatric surgery [but the solution is] a healthy balanced diet, and not for just a month or two but forever."

Like medical treatment regimens, nutritional intervention requires strict adherence, in this case to a rigid dietary model that determines what patients may eat, in what quantities, where, when, with whom, and how often [2]. They must eat correct foods in correctly sized portions, and at correct times. An endocrinologist's comment unintentionally reveals the moralizing nature of this 
endeavor: "This involves a change in eating habits. People have to eat healthy independently of whether they're thin or overweight. This is what we try to teach them, that they have to learn to eat in a civilized way" [my emphasis]. The optimum diet is administered to patients as if it were a medicine. In the words of a pediatrician, "We try to improve matters by modifying their pattern of physical activity and eating habits. But they will always be predisposed to obesity; the diet is like their medicine." Paradoxically, physicians correct their patients' tendency to diet compulsively (if ineffectively) by putting them on another diet, this time one that channels the patient's obsession with food and eating toward the biomedical model of optimal nutrition.

Several of the physicians interviewed said that they try to personalize the diets they prescribe according to the patient's age, weight, general state of health and medical history, putting particular emphasis on the distribution of food groups, their nutritional content, their distribution throughout the day and how they are prepared. Although these considerations are important, they have the effect of standardizing rather than personalizing medical recommendations because they are unrelated to the circumstances that lead people to make dietary choices. "What we always try to do," a pediatrician explained, "is to get obese people to change their attitude. If they believe they are on a diet, then they are not cured. When they go to a restaurant and choose a salad without thinking that they are on a diet... when they automatically walk up the stairs to get to the third floor... that is when they are cured."

Like many other diets, however, medically prescribed dietary and exercise regimens often fail. Although some patients manage to lose some weight temporarily, the long-term results are disappointing and unsatisfactory for clinicians. As Garrow [43] has shown, the majority of obese patients who start dietary treatment abandon it, and those who lose weight generally gain it back. Weight gain is attributed to patients' inability to follow instructions and remain on a diet. Responsibility for the failure of treatment is thus displaced from the physician onto the patient. One endocrinologist stressed that "The battle against obesity is constant. I understand that it's hard for them, but patients have to stay on their diets. People just don't follow through; they've lost their will power.” In physician accounts, obese patients come through as disobedient patients. "Their problem," another endocrinologist complained, "is that they can't follow instructions; they have no will power. The success rate of therapy is very low. This is a thankless specialty, and most of the patients I see are not at all prepared to make the effort necessary to improve.”

Missing from these responses is any consideration of the possibility that dietary intervention may not be the best solution for all patients, or for all types of obesity. One pediatrician firmly rejected this idea: "The treatment fails if you prescribe it and it doesn't work. If patients 'don't want' to start a treatment, like going on a diet and staying on it, is that a treatment failure or a lack of conscientiousness?" In the physicians' estimation, patients who are uncommitted to the treatment and therefore do not follow medical recommendations conscientiously are undermining their doctors' efforts to help them get well.

\section{IF OBESITY IS A DISEASE, IS IT MY FAULT I'M SICK?}

The notion of the human body as a project that is both social and individual, an entity under construction [44], is useful for understanding how ideas about the size and shape of the socially and medically correct body can affect people's daily lives by legitimating particular forms of stigmatization. Stigmatization is a process that unfolds in social interaction, discrediting people as "not normal" or "deviant" [45]. Several studies have focused on the various ways in which obesity is stigmatized and how this affects a person's position in society [46-48]. They point out that young fat people suffer disproportionately because stigmatization is both transversal and longitudinal: it affects all social relationships, and lasts for the whole of the life cycle. People who regard their body weight as "normal" tend to see overweight as a consequence of deviant eating behavior. Overweight individuals are held personally responsible for their condition, and experience social exclusion and the reduction of their identity to a single, stigmatizing characteristicfatness - while all other personal attributes become secondary. Those stigmatized in this way are caught in a vicious circle. Accepting the negative judgments of others, young people lose self-respect and become even more isolated socially.

The demonization inflicted on the overweight is shared by most of the young people interviewed for this study. The transformation of obesity into a disease has not made their lives easier because health professionals consider it a self-inflicted problem rather than one to which they are predisposed by the nature of consumer society. The insistence that successful treatment depends on patients' ability to regulate their eating habits and exercise is the most common argument used by the young people I interviewed to blame themselves for being fat. A 15-year-old boy explained, "My hobbies are watching TV and playing games on my computer or my Play Station. I spend six hours a day in this room. In general I feel sort of guilty. When I'm in the middle of a game I think I should be out walking." Self-neglect prompted by personal problems is also offered as an explanation for weight gain and used as a self-incrimina- 
ting argument. A 35-year-old woman framed the problem in behavioral terms: "You start letting yourself go, getting fatter and fatter. Yes, it's our fault. I put on 22 kilos when I was pregnant, and when we split up I got really depressed and gained a lot more weight. I didn't feel like doing anything. What did I do? I just ate! Of course it's our fault."

Obese people internalize medical and social judgments, accepting that they are incapable of controlling themselves and sticking to a diet. As a 34-year-old woman said, "You feel guilty, powerless, angry at yourself... and ashamed." Shame is a recurrent theme because, somehow, they feel like sinners unable to resist the temptation of eating. A 32-year-old man said, "Obesity is the result of not making an effort and letting myself go." They also feel that they are weak because they have always been easily led by others. As a 23-year-old woman confessed, "When I was growing up I was constantly snacking. My mother did, so I did too." A 23-year-old woman invoked biological predisposition, but quickly returned to individual behavior: "My problem is genetic, but my eating habits don't help any. At one point I weighed 160 kilos. That's not just genetics."

Although the majority of the adolescents and young adults interviewed blamed themselves for their weight problems, they also frequently mentioned other factors. A 32-year-old man explained, "I was always very athletic, but then I had to quit because I was working and going to school... I started putting on weight... My job doesn't help much; I spend the whole day sitting down.” Other themes that surfaced in interviews were the way life is organized in modern industrial society, work or class schedules that leave little time for other pursuits and, as a 33-year-old woman pointed out, the relationship between income and food choices: "Your diet has a lot to do with your salary. If you have enough money... you can buy different things than if you have a smaller food budget. You have to go for what's cheaper, not better quality, and that's a handicap because when it comes to taking good care of yourself, eating a healthy diet, if you can't invest the money, it's a lot harder." A 26-year-old woman talked about time pressure: "Well, it's everything! You spend the whole day at work, you get home, and you eat anything that's quick and easy to prepare, you know? I blame work, this whole way of life."

Not all young people, however, consider themselves to blame for their condition. Some of the patients interviewed refused to be labeled in this fashion and pointed out that there are other, non-behavioral reasons for weight gain independent of will power. A 15-year-old girl argued, "With what they eat, some people should be really fat, but they're not. I don't eat a lot. In fact, I don't eat much at all.” Fat people are not necessarily big eaters, but despite scientific evidence that not all bodies accumulate the same amount of fat if they consume the same amount of food [49], doctors always warn their overweight patients to eat less. As an endocrinologist put it, "The imbalance between what is consumed and what is expended can only be corrected by decreasing intake." Some of those interviewed also contest their doctors' belief that adopting a healthy lifestyle is the solution, because in their experience it has not helped. A 33-yearold woman protested, "Everyone thinks that you don't look after yourself, that you don't know how to eat properly. They think that you're the problem because you eat too much, because you snack between meals. That's not true. Stress makes me fat. If you have a thyroid problem like I do, everything you eat makes you gain twice as much weight as other people. No one realizes that. I ride a bike, I walk, I go swimming... and I still have a lot of trouble losing weight."

Whether people believe they are ill because they are fat depends in large measure on their age and degree of obesity. The youngest informants tended not to think of themselves as ill because their excess weight does not prevent them from engaging in normal activities and there is no sign of any physical cause or associated pathology. Some, despite being fat, said they felt fine but, as a 21-year-old woman put it, if you don't watch your weight “it could turn into a disease... But I don't see it as an illness. If I hadn't been able to keep it under control, then it would be more like an illness, right?” A 17-yearold girl drew a subtle distinction between feeling uncomfortable in one's body and defining oneself as ill: "In my case, no, I'm not sick. But does it affect me? Yes, definitely.”

At the higher end of the age range, especially among those who had struggled unsuccessfully for years and tried all available means to reduce their weight, the most corpulent informants were more likely to see obesity as a disease even though they recognized that health concerns were not the primary factor motivating them to try to lose weight. A 34-year-old woman said, "I'm fat, and that's that! ... I always used to say it was a question of health [before gastric bypass surgery]... but now I see that it was all about how I look, I realize it more and more every day. You should pay more attention to your health, that's the main thing, I think obesity leads to problems."

Those with diagnosed genetic, hormonal or metabolic disorders stressed that they follow their doctors' recommendations to the letter but, as this woman argued, something beyond their control lets them down: "I have a lot of self-control, and when I decide not to do something, I don't do it. If I have to eat less, I eat less. I don't know what's wrong." Those who defined their weight problem as an illness typically had complications associated with 
obesity, like the 33-year-old woman who said, "I want to feel good, go for a walk and not get out of breath, be able to do things and not feel like 'I'm tired, I don't know what's wrong with me.' I don't want this disease.”

Those who are closer to so-called extreme or morbid obesity were the most likely to believe they are ill and identify their condition as a disease, less because they may also suffer from diabetes or hypertension than because their weight makes daily activities-washing, getting dressed, going to work, and even sleeping-much more difficult. One 35-year-old woman commented, "For me obesity is more a health issue than a matter of how I look. I can feel it when I go upstairs because I get tired. When I walk and talk at the same time, I get out of breath. If you don't take care of yourself, it catches up with you."

In most other afflictions, being identified as sick exempts the sufferer from blame. Although this is not the case for the obese, at least some of the persons interviewed believe that only the recognition of obesity as a chronic disease will allow them to challenge the stigma of being regarded as a sort of "nutritional delinquent". As a 24-year-old woman put it, "I would like to say that obesity is one of the least understood diseases, because those who don't have it believe that fat people just don't care how we look. Then we feel like we have to hide when we eat so they won't pass judgment on us, as if we were criminals". Nevertheless, as a 31-year-old man noted, freeing oneself from blame and the guilt it induces is a difficult task because of the ambiguous status of obesity as both a disease and a personal failing: "Although I have always been obese, I have never got used to it. I find it hard to put up with all the comments made by other people, my parents and my wife. It's difficult to convince people that obesity is a medical problem, not just a personality issue”.

\section{CONCLUSIONS}

When obesity is approached as a problem of excess weight attributable mainly to a positive energy balance, the nature and complexity of both the biological and the cultural factors that contribute to its origins and development tend to be oversimplified. This is evident both in public health strategies to prevent obesity, and in the narratives of health professionals and the obese adolescents and young adults they treat. In Catalonia, public debate on the causes of the rapid rise in obesity rates is not polarized, treating "individualizing" or "systemic" frames [3] as mutually exclusive, but invokes both. The negative consequences of a lifestyle in which both work and leisure are largely sedentary and transportation largely mechanized are pointed out, but individuals are also blamed for succumbing too easily to the temptations of cheap and abundant fast food instead of devoting the necessary time to food shopping and preparation of healthy meals.

Although the link between sociocultural factors and obesity conceptualized as an "avoidable" disease may seem intuitively obvious, demonstrating this connection is by no means simple. Hardly any studies empirically support a causal relationship between so many and varied factors and the rise in obesity rates. In Catalonia all these factors are present, but it is very difficult to know to what extent they have influenced eating habits, and whether this influence has necessarily been negative. Although certain obesogenic factors are repeatedly singled out and emphasized, especially sedentary lifestyles and an impoverished diet increasingly dependent on fast food, the main strategy continues to be motivating individuals to change their eating habits through nutritional re-education. This, of course, is a much easier task than modifying the structural forces that condition individuals' dietary choices and their ability to manage their health.

In a lipophobic society, overweight is taken as a sign of both self-neglect and social irresponsibility. Obese individuals endanger their own health, which makes them less productive; and the treatment they require not only for obesity but also for associated conditions such as hypertension and diabetes burdens society with rising health care costs. Obesity in young people is thought to be a result of ignorance, willful or otherwise, about the need for regular exercise and what constitutes a balanced diet. Young persons who are obese embody the evils that afflict obesogenic societies: consumerism, complacency, and lack of self-control. Their corpulence is widely regarded-especially by health professionals-as a selfinflicted condition resulting from a behavioral choice.

Sufferers are not only blamed for their condition; they blame themselves for it as well. Medical approaches to obesity focus on the foods people consume, leaving out of the picture the many and complex reasons why people eat certain foods and not others. As a result, treatment is oriented toward modifying dietary habits considered inappropriate, without taking into consideration the patient's subjectivity or the social and cultural forces that give rise to an unbalanced diet. Health professionals' lack of interest in the non-nutritional causes of obesity to which their patients' point makes young obese persons doubt the authenticity of their own experience, which only serves to increase their sense of guilt.

In a lipophobic context, body size serves to classify persons. Slenderness is a sign of beauty, health, and self-discipline, while obesity signifies the opposite. For young obese persons, fatness represents a threefold failure: personal, social and medical. Often they are much less concerned with the possible health consequences of obesity than they are with losing weight in order to es- 
cape the emotional and social torture of being fat. Rejecting for having an unattractive body that exceeds the boundaries of what is considered normal, most patients heed the anti-obesity messages generated and generalized by biomedicine and the health products industry, and decide to put themselves on a diet. What begins as a limited-time strategy to achieve a particular end-losing weight - then becomes a state of being with a significant impact on all aspects of everyday life. Health professionals should carefully consider the consequences of the progressive medicalization of fatness and its stigmatizing effects.

\section{ACKNOWLEDGEMENTS}

This article is part of a broader program of research carried out through two projects: The emergence of obesogenic societies: obesity as a social problem (CSO2009-07683, 2009-2012) and Images and experiences of obesity in young Catalans (AJOVES 2008 00017). I am grateful to both institutions, my colleagues, and especially to the young women and men who agreed to be interviewed for this project. Special thanks to Susan M. DiGiacomo, Ph.D., my colleague in the Department of Social Anthropology, Philosophy and Social Work of the Universitat Rovira i Virgili, for translating and editing the final version of the manuscript.

\section{REFERENCES}

[1] Gracia-Arnaiz, M. and Comelles, J.M. (2007) Thou shalt not eat. Narratives on food, body and gender in the new millennium. (No comerás. Narrativas sobre comida, cuerpo y género en el nuevo milenio.) Editorial Icaria, Barcelona.

[2] Gracia-Arnaiz, M. (2009) Learning to eat: The establishment of dietetic normality on eating disorders. Food, Culture and Society, 12, 191-216. doi:10.2752/175174409X400738

[3] Lawrence, R.G. (2004) Framing obesity: The evolution of news discourse on a public health issue. The Harvard International Journal of Press/Politics, 9, 56. doi:10.1177/1081180X04266581

[4] Poulain, J.P. (2009) The sociology of obesity. Presses Universitaires de Paris, Paris.

[5] Saguy, A. and Ward, A. (2011) Coming out as fat: Rethinking stigma. Social Psychology Quarterly, 20, 1-23.

[6] Fischler, C. (1990) The (ho)mnivore. Odile Jacob, Paris.

[7] Csergo, J. (2009) When the obesity of gourmands becomes an ailment of civilisation. Medical discourse 1850-1930. In: Csergo, J., Ed., Too Fat? Obesity and Its Representations, Éditions Autrement, Paris, 14-29.

[8] Vigarello, G. (2010) The metamorphoses of fat. Ed. Seuil, Paris.

[9] Lupton, D. (1994) Medicine as culture. Sage Publications, London.

[10] Brumberg, J.J. (1988) Fasting girls. Harvard University Press, Cambridge.
[11] Saint Pol, T. (2010) The desirable body. Presses Universitaires de France, Paris.

[12] Gracia-Arnaiz, M. (2009) Obesity as a social problem: Thoughts about its chronic, pandemic and multi-factorial character. In: Fainzang, S., Hem, H.E. and Risor, M.B., Eds., The Taste for Knowledge: Medical Anthropology Facing Medical Realities, Aarhus University Press, Aarhus, pp. 183-198.

[13] Basdevant, A. (2009) The purpose and abuses of the contemporary medical definition. In: Csergo, J., Ed., Too Fat? Obesity and Its Representations, Éditions Autrement, Paris, pp. 112-122.

[14] Apfeldorfer, G. (2009) From a lack of slimness to a lack of beauty, the obese body is an embarrassment. In: Csergo, J., Ed., Too Fat? Obesity and Its Representations, Éditions Autrement, Paris, pp. 136-149.

[15] Elias, N. (1939) The process of civilization. Fondo de Cultura Económica, Madrid.

[16] Sontag, S. (2005) Sickness and its metaphors. Aids and its metaphors. Suma de Letras, Madrid.

[17] DiGiacomo, S.M. (1992) Metaphor as illness: Postmodern dilemmas in the representation of body, mind and disorder. Medical Anthropology, 14, 109-137. doi:10.1080/01459740.1992.9966068

[18] Bordo, S. (1993) Unbearable weight: Feminism, western culture, and the body. University of California Press, Berkeley.

[19] Regnier, F. (2009) Obesity, tastes and consumption. Integration of eating guidelines and social belonging. Revue Française de Sociologie, 50, 747-773.

[20] Gracia-Arnaiz, M., et al. (2012) Poor fat youngsters! Obesity and young people's lives. Servei de Publicacions URV, Tarragona.

[21] Hacking, I. (2010) Normalisation. The epidemic of obesity. Lesson number 3. http://www.college-de-france.fr/site/historique/ian_hackin g

[22] Le Guen, J.M. (2005) Obesity: The new French disease. (Obesité, le nouveau mal français.) Armand Colin, Paris.

[23] World Health Organization (WHO) (1977) International classification of diseases. 9th Edition, WHO, Geneva.

[24] WHO (1998) Obesity: Preventing and managing the global epidemic. Working Group on Obesity. World Health Organization, Geneva.

[25] Heshka, S. and Allison, D.B. (2001) Is obesity a disease? International Journal of Obesity, 25, 1401-1404. doi:10.1038/sj.ijo.0801790

[26] Rubio, M.A., et al. (2009) Consensus foe evaluating overweight and obesity, and the establishment of criteria for therapeutic intervention. http://www.seedo.es

[27] Aranceta, J. (2008) Infant obesity: New eating habits and new health risks. In: Díaz, C. and Gómez, C., Eds., Food, Consumption and Health, Fundació "la Caixa”, Barcelona.

[28] Serra-Majem, L.L. and Ribas, L. (2010) Trends in obesity, and eating and physical activity habits in Catalonia revealed by Catalan surveys and the analysis of trends in overweight 
in infancy and adolescence using several national surveys. http://www.gencat.cat/salut/depsalut/html/ca/dir2649/tenobe si2011.pdf

[29] (2008) National survey on health in Spain 2006. http://www.msps.es/estadEstudios/estadisticas/encuestaN acional/encuesta2006.htm

[30] Ortiz, R. (2010) Epidemiological report on obesity and public policies for its prevention. http://www.ua.es/webs/opps/docs/informes/INFORME_D E_EPIDEMIOLOGIA_Y_POLITICA_DE_OBESIDAD_ OPPS.pdf

[31] WHO (2004) Global strategy on diet, physical actitivity and health.

http://www.who.int/dietphysicalactivity/strategy/eb11344 len/index.html

[32] NAOS (2005) Strategy for nutrition. Physical activity and the prevention of obesity. Agencia Española de Seguridad Alimentaria, Madrid.

[33] PASS (2006) Comprehensive plan for the promotion of physical activity and a health diet. Departament de Salut, Generalitat de Catalunya, Barcelona.

[34] Serra, J., et al. (2003) Overweight and obesity. Evaluation of the objectives of the health plan for Catalonia for the year 2000. Medicina Clínica, 121, 47-50.

[35] Serra-Majem, L.L., et al. (2007) Tendencies in the nutritional status of the Spanish population: Results of the nutricional monitoring systemin Catalonia. Revista Española de Salud Pública, 81, 559-570. doi:10.1590/S1135-57272007000500011

[36] Tojo, R. (2008) Obesity in infants and children. A public health crisis. In: Martí, R., Ed., Tribunas de Nutrición, Unidad Editorial, Madrid.

[37] Lang, T. and Rayner, G. (2007) Overcoming policy cacophony on obesity: An ecological public health framework for policymakers. Obesity Reviews, 8, 165-181.

$$
\text { doi:10.1111/j.1467-789X.2007.00338.X }
$$

[38] Lang, T. and Hesman, M. (2004) Food wars: The global battle for mouths, minds and markets. Earthscan, Sterling.

[39] Gracia-Arnaiz, M. (2010) Fat bodies and thin bodies: Cultural, biomedical and market discourses on obesity. Appetite, 55, 219-225. doi:10.1016/j.appet.2010.06.002

[40] Bourdieu, P. (1972) Outline of a theory of practice. Esquisse d'une théorie de la pratique. Éditions Droz, Genève.

[41] Giddens, A. (1984) The constitution of society. University of California Press, Berkeley.

[42] Delormier, T., Fronlich, K.L. and Potvin, L. (2009) Food and eating as social practice-Understanding eating patterns as social phenomena and implications for public health. Sociology of Health \& Illness, 31, 215-228. doi:10.1111/j.1467-9566.2008.01128.x

[43] Garrow, J.S. (1988) Obesity and related diseases. Churchill Livingstone, Edinburgh.

[44] Shilling, C. (1993) The body and social theory. Sage Publications, London.

[45] Goffman, E. (1963) Stigma. The deteriorated identity. Amorrortu, Buenos Aires.

[46] Cahnman, W.J. (1968) The stigma of obesity. The Sociological Quarterly, 9, 283-299. doi:10.1111/j.1533-8525.1968.tb01121.x

[47] Sobal, J. (1995) The medicalization and demedicalization of obesity. In: Maurer, D. and Sobal, J., Eds., Eating Agendas: Food and Nutrition as Social Problems, Aldine de Gruyter, New York, 67-90.

[48] Tibère, L., et al. (2007) Obese adolescents in the face of stigmatisation. Obès, 2, 173-181.

[49] Alemany, M. (2003) Mechanisms for controlling body weight. Revista de la Reial Acadèmia de Medicina de Catalunya, 18, 44-49. 